\title{
Role Of Participatory Gis In Creating Spatial Database For Slum Development- A Case Study Of Kalaburagi City
}

\author{
Anil Gandhi ${ }^{1, *}$, Dr. Sulochana Shekhar ${ }^{1}$ \\ ${ }^{I}$ Department of Geography, School of Earth Sciences, Central University of Karnataka,

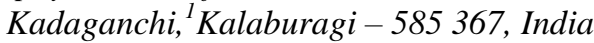

\begin{abstract}
A Slum expansion due to urbanization presents significant challenges for human health and wellbeing. We outline here key dimensions of the consideration, pointing to areas where public participation can make a particularly strong contribution. We argue for enquiry that considers multifaceted progressions operating at various geographical scales, linking arguments about 'global health' with the more local and individual processes that contribute to health determinants. Recent years have observed a flourishing GIS application to indigenous geographical knowledge to 'official' spatial data. By incorporating various forms of public participation to Geographical Information Systems as 'Participatory GIS' (PGIS) offers an answer to the critiques of GIS which were prevalent since long time. Participatory mapping and transect walks were used to inform the research and intervention design and to begin building community relations in preparation for projects. Although support systems for slum development have now undergone research, but is not reflected in their practical application. A better understanding of the relationship between participation practices for slum development is needed in order to improve the role of the latter. We argue that communicative and analytic approaches to current scenarios should be pooled. The present paper observes the potential of the expanding the outreach of PGIS to augment the customary techniques to empower them with modern tools. The problem was examined in a practical scenario in which the techniques were practiced simultaneously. This work evaluates and explores aspects of the control and ownership of geographical information, representations of local and indigenous knowledge based approaches with some potential future technical and academic directions. The results show that new approaches not only differ from the involvement of traditional practices, but they also differ from each other on the basis of their type of participation. The results indicate that participatory GIS is an effective harmonizing means of public participation and augment the traditional unmediated techniques. We have developed a conceptual framework for physical characteristics and evaluation of knowledge with the role of public participation as central theme. Combined with the notion of storytelling, we are certain that this result in a perspective for PGIS has potential for future applications. The paper provides new wider approach and dimensions for future research. Furthermore, the method lays down the foundation for collaborative community research partnerships.
\end{abstract}

Keywords: Participatory GIS, Spatial Database, Slum Development, Urban studies.

\section{INTRODUCTION}

Participatory GIS (PGIS) is the amalgamation of local information as well as stakeholder's perceptions in GIS. PGIS in the perspective of planning in coming together of social activity, such as the combination of input from grassroots organizations with government decision making and expertise in specific places or grounded topographies [1]. P-GIS are likely to be implemented in a participative style and make use of local information; contained by which indigenous spatial knowledge is a distinct class. Such as there is an often-made statement that this use of GIS is a tool for improved governance. PGIS is useful for emerging civic awareness of local situations, also to strengthening community associations as a component in encouraging people's empowerment. In definite cases, it is often tough to differentiate in the middle of these, the 'empowerment' is generally not always the ultimate aim when the awareness-raising or institution-building [2]. PGIS preparation is geared in the path of community empowerment through dignified, demand-driven, user-friendly and combined uses of geo-spatial technologies. GIS based maps and spatial exploration becomes most important conduits in the procedure. A good PGIS preparation is embedded into long-lasting spatial decision-making processes, is flexible, adapts to different socio-cultural depends on multidisciplinary enabling skills and builds essentially on visual language. The practice integrates numerous tools and procedures while regularly depend on the combination of "expert" skills with socially distinguished local knowledge. It encourages collaborative participation of stakeholders in creating and supervision of spatial information and it uses information about specific landscapes to enable broadly-based decision making procedures that support effective communication and community support [3]. 
PGIS can be divided into two extensive themes, namely, more general access of the several stakeholders towards the information in the GIS and the presence of information from several stakeholders in a GIS. The main aim of this is to practice GIS to provide information that can reinforce involvement of communities or downgraded groups in decision making [1]. PGIS is evolving as a individual division of two formerly separate activities: technology-based spatial analysis and participatory democracy. By its origins in the GIS and society proceedings in the mid-1990s, PGIS has developed to a level where in 2002, Obviously, there is a variety of scholars, experts, developers, and activists who share a slightly collective vision that the practice of GIS is graphical along with its spatial analysis capabilities existing a new and distinctive prospect for community variation and impact. Public participation has recently originated to be assumed as an integrated fashion [4]. During the 1990s, main blames were regarding the technology's isolation and exclusive assets generated the Participation GIS (PGIS) program which objectives were to develop alternative methods that democratize the use of the technology, generate easy access to government-generated data, and incorporate local information [5]. PGIS is the preparation of collecting data using traditional methods such as interviews, queries, focus groups, altogether using some form of paper maps to permit participants to record spatial details. This information is then digitised so that it can be analysed and cross-examined using the power of the computer GIS software, and also show that several outputs can then be communicated using computer-drawn map outputs [6].

Slum according the Census 2011, has been defined as residential areas where houses are in poor condition for human occupancy by explanations of disrepair, overpopulation, defective arrangements and design of such buildings, narrowness or broken down arrangement of street, nonexistence of ventilation, light, or sanitation amenities or any combination of these factors which are unfavorable to the safety and health [7]. Slums have become a procedure of an essential part of the occurrences of urbanization in India. The expansion of slum is due to the compression of the population mostly on un-used, un-protected and un-suitable government land. Deprived of finding appropriate solutions to the housing glitches of a majority of urban dwellers, public and private decision makers will not be able to meet the challenges of sustainable urban development. The first step is to quantify and locate the slum population and is to improve an operational definition of the term "slum". Experts at an UNHABITAT meeting held in 2002 agreed on the following definition: "A slum is a contiguous settlement where the inhabitants are characterized as having inadequate housing and basic services"[8]. Describing slum raises several conceptual issues, making it difficult to specifically estimate the slum population living in urban areas. Perceptions and definitions of slums vary from country to country and even in the same country, slum settlements may be known by different names [9].

\subsection{Study Area}

\section{DATA AND METHODS}

Kalaburagi means stony land in Kannada. The district is situated in the northern part of Karnataka State. Earlier, Kalaburagi was a district of Hyderabad Karnataka area but after re-organization of states it became a part of Karnataka State [10]. Kalaburagi city is directed by Municipal Corporation which comes under Kalaburagi Metropolitan region. As per provisional reports of Census India, population of Kalaburagi in 2011 is 533,587; of which male and female are 271,660 and 261,927 respectively [11]. Following is the sample of study area.

1. Vijay Nagar Area Ward No: 40.

2. Vijay Nagar with 5-32 Acres slum area of Kalaburagi city with the population of more than 1065, and 213 House Holds as per 2011 Census.

3. Vijay Nagar Slum area is near to the Bus stand. (Fig 1 shows the study area).

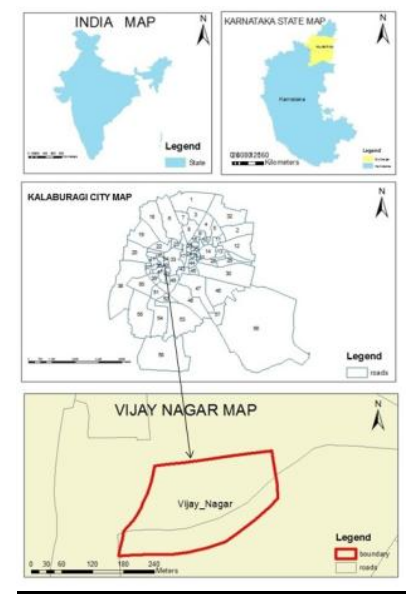

Figure 1: Location of sample study area 
Role Of Participatory Gis In Creating Spatial Database For Slum Development- A Case Study Of..

\subsection{Objectives}

The current work intended to achieve the following inline objectives keeping the universal goal of better slum level development and planning:

1. To appraise role of participatory GIS (PGIS) for slum level planning.

2. To generate spatial database for slum development.

3. To conduct a model study area at Kalaburagi city.

\subsection{Datasets and Tools Used}

The current work utilized the high resolution satellite imagery as a reference tool to evaluate the precision of the datasets being collected, stored and generated to the spatial database. It utilized the commercial GIS tools like ArcGIS10.x to perform the mapping and digitization with precise accuracy level. Along with this, the current work utilized the following datasets and instruments to carry whole research work:

1. Data of Slums was collected from Karnataka Slum development Board, Kalaburagi as secondary source.

2. Geo-eye high resolution satellite imagery (0.6 m resolution) of April 2013.

3. GPS eTrex Instrument

4. ArcGIS software's for mapping and digitization.

5. Google Earth for visualization and reference checking of the collected information's from PGIS approach.

\subsection{Methodology}

1. Local people of the Vijay Nagar area were communicated to Participate Voluntarily to collect the house hold data.

2. Three volunteers were trained to use GPS instruments.

3. House to house GPS survey and questionnaires was collected by volunteers, each houses had to be numbered.

4. After the completion of the survey, GPS points were overlaid on the Geo-eye satellite image, GPS points of houses numbered a spatial join could be carried on the GIS software to link the questionnaires as an attribute data for the corresponding house.

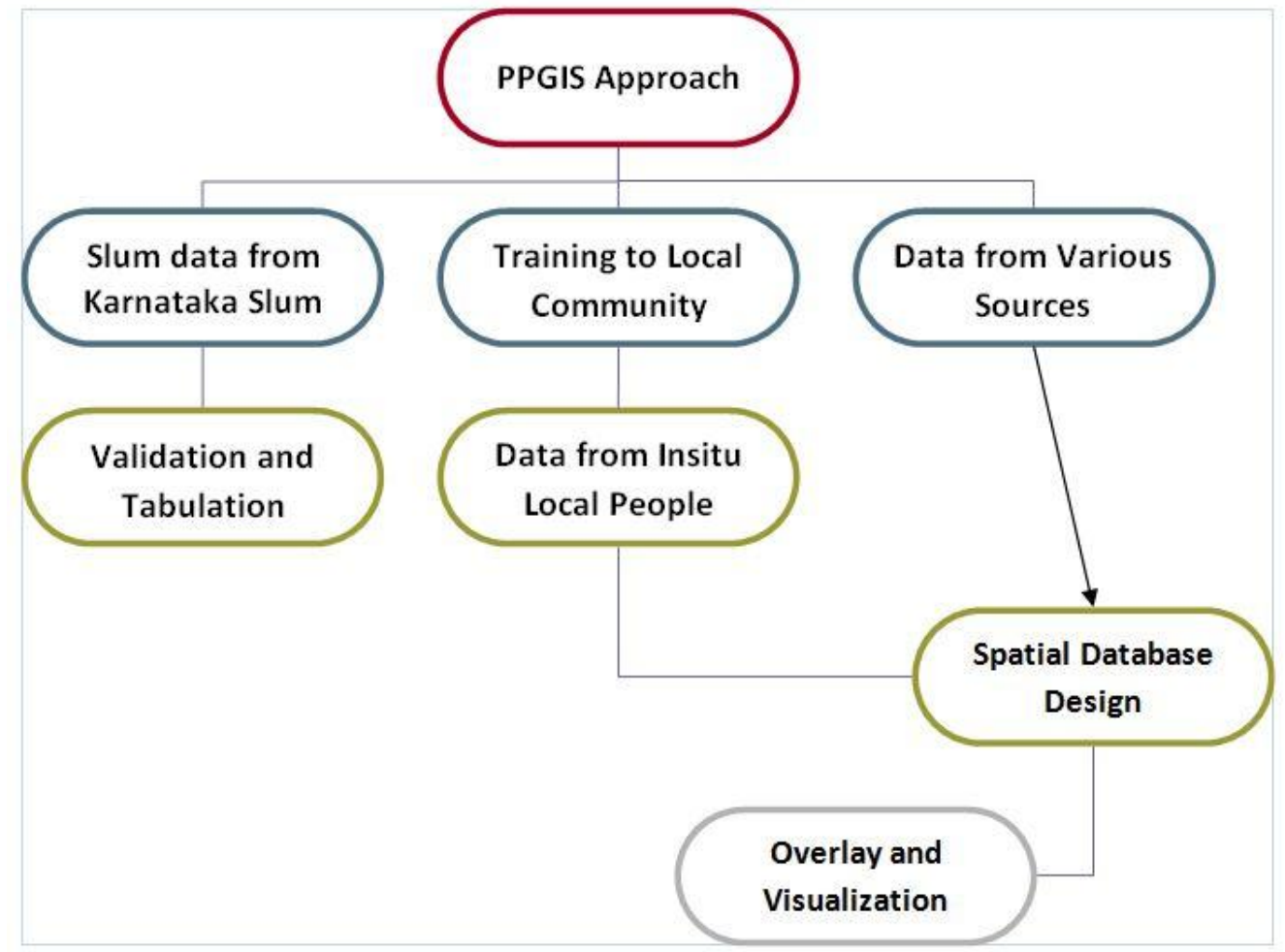

Figure 2: Illustration for methodology being used.

Figure 2 illustrates the complete sequence of all the activities being performed to achieve the discussed objectives of the current work. 


\subsection{Attribution of Data}

\section{RESULTS AND DISCUSSIONS}

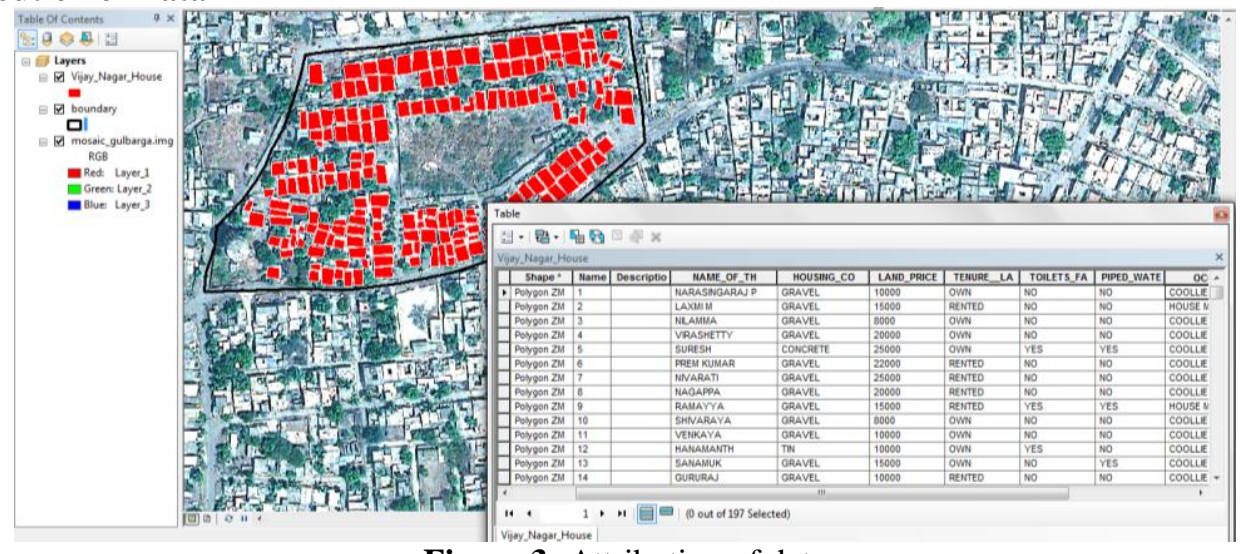

Figure 3: Attribution of data

Above figure 3 explains the data attribution for slum areas. It represents the tabular or textual data describing the geographic characteristics of features. Attribute data provides the information appended in tabular format to each of the spatial features. The spatial data is the 'where' and attribute data can contain information about the 'what, where, and why'. Attribute data provides characteristics about spatial data. Attribute data were obtained from a number of sources like slum board, town planning and management departments, policing and fire departments, environmental groups, online media.

\subsection{Individual slum house information}

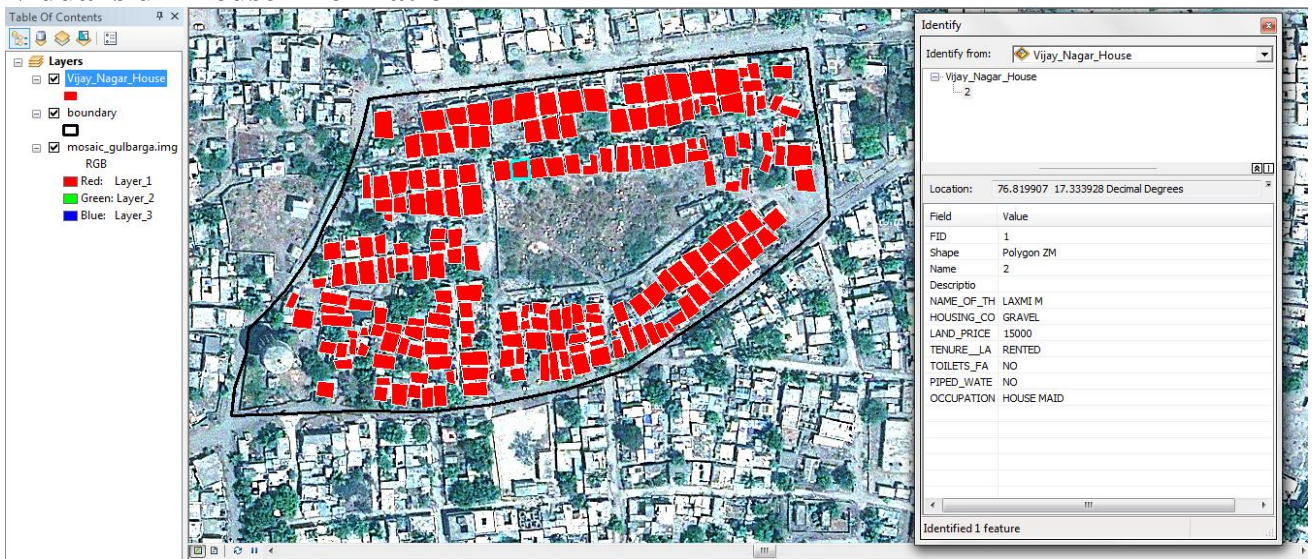

Figure 4: Individual slum level information

We are aware of the act that slums are squalid sections of a city or town, areas in which most inhabitants are in or near poverty and have been created in various locations; where they arise depends upon political and economic conditions of a community, which are usually the most stigmatized parts of a city or town. In the mind of the general public, the disgrace and stigma of the slum area showers onto the people who inhabit it. People also habitually raise the concept of "social disorganization" to describe the slum. In order to have individual slum level information is very much crucial for implementing and executing slum developments programs. In this regard figure 4 provides the vertical information about individual slum level information. 


\subsection{Responses from questionnaire survey}

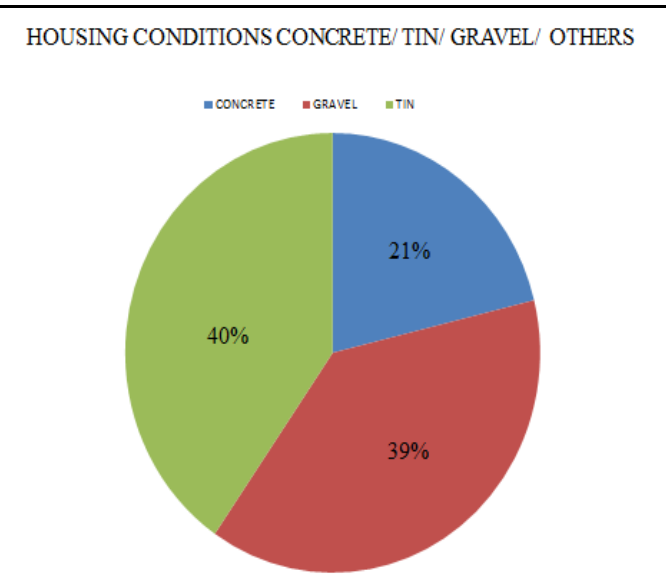

(a) Housing Condition

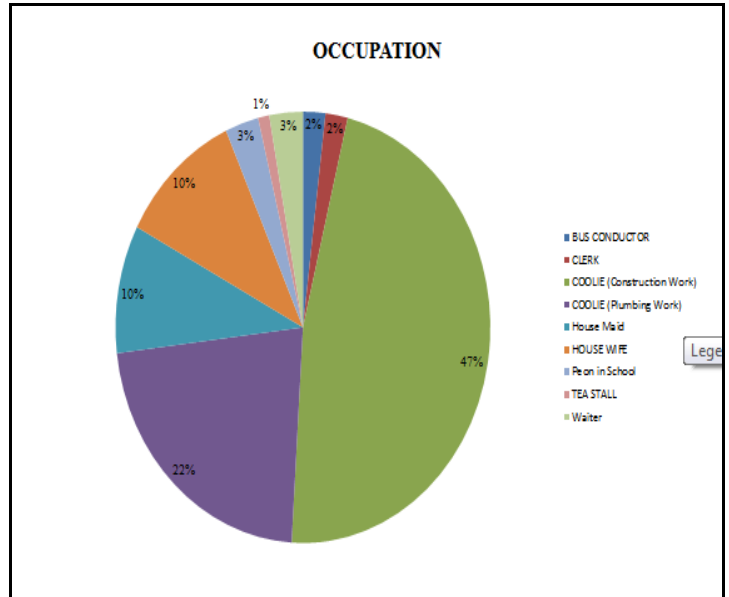

(b) Occupation status

From our preliminary consciousness know that socio-economic prominence confirms the individuals or population's living standard, life style along with over all development status. The housing condition, occupation are the most important elements in the study of socio-economic status of any population group. Besides these elements land ownership and sanitation condition were also taken into consideration. As Slums are an unhygienic place for human settlements. Poverty is a disjoint part of slum dwellers. So the slum population are normally extensively socially and economically backward. Poverty ominously touches the health, education, nutrition, birth and death ratio, sex ratio, life expectancy, the socio-economic status of the slum dwellers. Due to poverty economic status is lower, so education level is low, unskilled or low skills, so the socio-economic status of slum dwellers is low. Therefore, there is a need to study the socio-economic status of slum. In this regard 5(a) and 5(b) provides the housing condition and occupation status at slum level.

Slum area has various dirty places in very much unhygienic conditions. It is the adjustment with nature and conciliation with life's necessity to survive in worst condition. It is due to the vicious circle of poverty. The poverty is an unprecedented part of slum dwellers. So the slum population is backward socially and economically. Their socio economic status is low. The vulnerability of the urban poor is aggravated by the insufficient provision of basic public service which governs land and housing supply and property rights. Policy reforms are required in the areas of: Tenure security, property rights and land development regulations; Housing finance; and Service provision. Most of the urban poor do not have tenure security because their dwellings are:

1. built on public land; or

2. constructed on private property not belonging to the owner; or

3. built on shared title land; and/or

4. constructed without occupancy or construction permits; or

5. rented in slums without formal renting contracts

Without land titles, residents of informal or marginalized communities are in constant fear of relocation or demolition, and are prevented from benefiting from the land's productive uses. Housing tenure gives slum residents a guaranteed right to the land and their properties, thus enabling them to make investments to improve their living conditions.

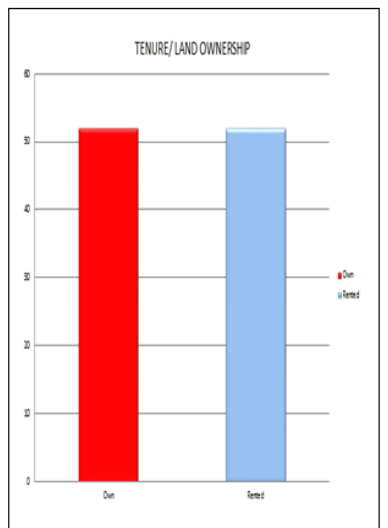

(c) Land ownership details

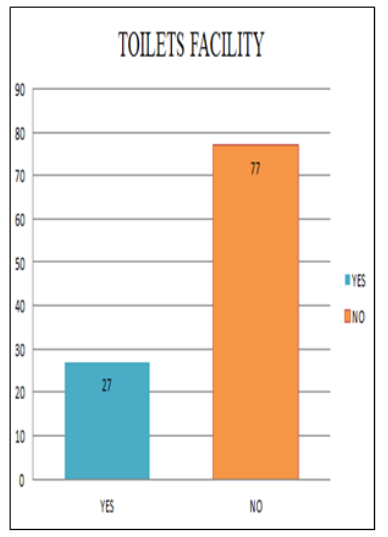

(d) Toilet facility status

Figure 5: Charts and Graph presenting responses of questionnaire survey 
Slums can roughly be categorized based on whether they are officially recognised by the state government (notified) or not (non-notified). Notified slums are legally entitled to the provision of basic services from the government. The NSSO survey shows that non-notified settlements have weaker infrastructure compared to their notified counterparts. The challenge of rapid and unplanned urbanization will continue to face over the coming decades needs no introduction. Of the 93 million slum residents in India, 81 per cent have inadequate access to sanitation, according to a 2008-09 National Sample Survey Organisation (NSSO) survey on the characteristics of slums. That is to say, they lack the facility of either an individual toilet or a shared toilet. They are enforced to be contingent on badly maintained and overcrowded toilet blocks or, have no form of toilet at all. Open spaces are thus the only option.

It is essential that it goes hand-in-hand for disseminating consciousness about the significant health. A readiness to pay exists in markets for what should be perceived as an essential good (along with clean water and electricity). Researchers are evaluating the effect of improving communal toilet facilities, and implementing innovative systems for facility maintenance, on the use of community toilets in Kalaburagi, Karnataka, India. Graphs in the figures 5(c) and 5(d) provides the overview and scenarios of land ownership along with the toilet facility status respectively. People residing in the poverty stricken areas suffer poor environmental health due to unsafe drinking water. They also have meagre sanitation comportment and lack of sanitation due to rapid and haphazard urbanization leading to crowded and unhygienic settlements. The vulnerable population, especially women and children, are being targeted by various schemes to improve their health and wellbeing. Specifically, the focus is on improving access to safe drinking water and guaranteeing access to better sanitation facilities. Additionally, the dissemination of better hand washing practices and other hygiene behaviors leads to a reduction in water-borne diseases and ultimately a reduction in health costs.

\section{CONCLUSIONS}

The economically marginal people residing in urban slums need support not only on services but also on crucial livelihood issues. Proper GIS database provides crucial planning input for infrastructure planning, land use planning, environmental planning, slum development planning, local economic development, livelihood support and planning related to health and education. The issues associated to several co-existing realities of landscape, unequal access to data and technology, and the necessity for plurality and participation, to identify points in the process of GIS-supported production of information and decision-making where stakeholders can be engaged in the production and representation of knowledge. If it is embedded within participatory and collaborative processes, this engagement can be empowering for communities to avoid social and spatial marginalization for which traditional applications of GIS technology have sometimes been criticized.

In most cases this will entail the work of an interdisciplinary team and requires sincerity to defining problems and ascertaining an appropriate methodology in collaboration with stakeholders. In the slums projects the use of GIS was well-versed by an understanding of social and political implications to usage of the technology. GIS was more prominent in the research, and was kept in the background to work with slum dwellers. However, it was considered in a two-way process that endorsed stakeholders to express their descriptions of reality, and their visions for a desirable and feasible future. It also cares public contribution in contexts where all groups have the competences and means to access and use the technology. The significant point to draw particularly from the PGIS applications to slum community projects, is that necessary scientific and technological expertise needs to be complemented by expertise in collaborative methodology and participatory development.

Both the ease and difficulties of merging the participatory methodology are encountered through the process of data capture. This work has shown that it could be an effective, economical and reliable method. Moreover, the inclusion of such method gives an opportunity for participation and collaboration of different actors including the community thereby creating opportunities for data sharing and improved mutual understanding of actors necessary for collaborative slum upgrading interventions. However, the integration of methods and techniques has enabled the acquisition of rich information, which could not be possible to achieve in a single method, thus the limitation in one method can be amended by the strength of the other. In particular the interactive participatory mapping of experts and the community representatives' spatial knowledge translated into maps, gave a rich information base for this analysis.

\section{ACKNOWLEDGEMENT}

The authors would like to thank HUDCO/HSMI for the financial support provided for this study, The author also would like to thank Dr. Deepak Kumar and Raghavendra B R.

\section{BIBLIOGRAPHY}

[1] Kevin Musungu, SiddiqueMotala, and Julian Smit, A Participatory Approach to Data Collection for GIS for Flood Risk Management in Informal Settlements of Cape Town. Kevin.Musungu@uct.ac.za.

[2] M.K. McCall, Seeking good governance in participatory-GIS: A review of processes and governance dimensions in applying GIS to participatory spatial planning, Habitat International, 27, 2003, 549-573. 
[3] M.J. Bunch, T.V. Kumaran and R. Joseph, Using Geographic Information Systems (GIS) For Spatial Planning and Environmental Management in India: Critical Considerations, International Journal of Applied Science and Technology, 2(2), 2012, $40-54$.

[4] Marc Schlossberg, and Elliot Shuford, Delineating "Public" and "Participation" in PPGIS, URISA Journal, 16(2), $2005,15-26$.

[5] Lorlene Hoyt, Renu Khosla, and Claudia Canepa, Leaves, Pebbles, and Chalk: Building a Public Participation GIS in New Delhi, India, Journal of Urban Technology, 12(1), 2005, 1 - 19.

[6] John Forrester and Steve Cinderby, A Guide to using Community Mapping and Participatory-GIS.

[7] Housing Stock, Amenities \& Assets in Slums (Census 2011).

[8] Sulochana Shekhar, Modeling the probable growth of slums by using Geoinformatics, Indian J. Innovations Dev., 1(8), 2012, $588-598$.

[9] Sulochana Shekhar, Detecting Slums From Quick Bird Data In Pune Using An Object Oriented Approach, International Archives of the Photogrammetry, Remote Sensing and Spatial Information Sciences, 39(B8), 2012, 519 $-524$.

[10] Kalaburagi city website: http://gulbarga.nic.in/

[11] http://www.census2011.co.in/census/city/453-gulbarga.html. 